\title{
Forum on Early Warning and Early Response: A New Collaborative Effort
}

\author{
FEWER Secretariat
}

\begin{abstract}
This paper provides an introduction and overview of the Forum on Early Warning and Early Response (FEWER). Topics covered are: the mission statement, definitions, objectives and structure of the group as well as a description and evaluation of projectsin-progress. A member contact list, a synopsis of membership criteria and activities are included.

Précis

Cet article foumit une introduction et un aperçu du Forum sur l'Alerte Préventive et l'Intervention Rapide (Forum on Early Warning and Early Response-FEWER). Les sujets abordés sont: la formulation du mandat, la description, les objectifs et la structure de ce groupe, ainsi que la description et l'évaluation des projets en cours. Une liste de membres-contacts, un descriptif des critères d rencontrer pour devenir membre et une présentation des activités sont joints.
\end{abstract}

\section{History}

The Forum on Early Warning and Early Response (FEWER) was initiated in a meeting, September 3, 1996, at International Alert, London, by a group committed to moving forward early warning reporting and analysis in the larger interest of conflict prevention. At this meeting, a small steering committee was formed comprising Kumar Rupesinghe (Chair, International Alert, London), Sharon Rusu (UNDHA, Geneva), and Howard Adelman (Prevention/Early Warning Unit, York University, Toronto) to further develop the concept and the con-

FEWER Secretariat, c/o International Alert, 1 Glyn Street, London SE 115 HT, United Kingdom.

Phone: + 44-171-793-8383

Fax: +44-171-793-7975 sortium. An interim secretariat was assumed by one of the member institutions (Prevention/Early Warning Unit, York University, Toronto). As of June 1,1997 , the secretariat will be at International Alert where and will operate for about a year, or until sufficient funds are available for an independent secretariat. Furthermore, three pilot projects were initiated in West Africa, Central Asia and the Great Lakes region.

In a second meeting, January 24-25, 1997, at International Alert, London, the structure of FEWER was formalized. The Steering Committee was increased to five members (two of which are yet to be determined), a consortium of all participating organizations was formed, and Kumar Rupesinghe (International Alert, London) was elected chair. Government representatives were invited to participate as observers through membership in a contact group to ensure government participation.

The pilot projects provided an update on their activities. Discussion resulted in the replacement of the Central Asia project by one in the former Soviet Union in order to broaden the regional scope. The former lead agency on Central Asia (Center for Preventive Action, Council on Foreign Relations) will now carry out an evaluation of the three other pilot projects on West Africa (Prevention/Early Warning Unit, Centre for Refugee Studies, York University, Toronto), Great Lakes (International Alert, London) and former Soviet Union (Center for the Study and Prevention of Conflict, Russian Academy of Sciences, Moscow) due to its expertise in all three regions.

\section{Mission Statement}

The Forum on Early Warning and Early Response (FEWER) has been es- tablished as an independent and interdisciplinary consortium of academic research units, Non-Governmental Organisations(NGOs), and Inter-Governmental Organisations, including UN agencies, to provide decision makers with information and analysis to warn on the potential for violent conflict in order to prevent their escalation.

The purpose of FEWER is to establish an early warning network by:

- linking with regional and country research initiatives to ensure the collection of relevant country and regional information in a timely and systematic manner;

- developing strategic responses including but not limited to the prevention of violent conflicts that lead to displacement;

- strengthening of peace-making initiatives in areas of crises; and

- developing impartial trend analyses of risks in order to present options to major actors: United Nations, governments, international organizations, regional organization, NGOs and others.

FEWER views early warning as motivated by universal humanitarian rather than national or fractional interests. In this regard, FEWER's ultimate purpose is to provide early analysis of trends with the aim of enhancing peacemaking and capacity building for solutions in the areas of conflict.

\section{Definition}

FEWER defines early warning as the systematic collection and analysis of information coming from areas of crises for the purposes of: 1) anticipating the escalation of violent conflict, 2) development of strategic responses to these crises, and 3) the presentation of options to critical actors for the purposes of decision making. 


\section{Objectives}

- To provide an effective early warning and early action alert forum within a framework that promotes effective cooperation between NGOs, IGOs, academic institutions, and governments; and also maximizes the strengths, capabilities and roles/mandates of its members towards the common goals of prevention and early response.

- To ensure high quality standards and a coherent framework for assessing risks and reporting on the development of and consequences emerging from conflicts.

- To facilitate information exchange and dialogue amongst interested actors based on country/regional ongoing analysis.

- To facilitate, when possible and appropriate, coordination and cooperation of Consortium members on warning for early action by states and inter-governmental actors and NGOs. This will include assessments of policy options and analysis of the role of critical actors in order to provide recommendations for action.

- To identify funding options to ensure the viability of the Consortium and the promotion of information and analysis.

- To support early warning initiatives as integral to a process of prevention, risk assessment and response that lead to early action in the face of complex humanitarian emergencies.

\section{Principal Assumptions}

FEWER will strive to ensure quality of reporting and representation in its relationship with a diverse network of members whose capacities and resources are varied.

FEWER will ensure a balanced distribution of members to avoid a "northern-centric" structure and approach to reporting on areas of conflict.

FEWER will protect the confidentiality of its sources wherein disclosure may place individuals, family members or communities at risk of violation of their human rights.

FEWER will, through establishment of effective consultation and coordination mechanisms with relevant agencies and, taking into account various levels of communication technology available in zones of conflict, promote rapid access to information and analysis (local, country and regional) with a view to providing policy options and alternatives.

FEWER will establish membership criteria which are transparent and accountable to potential members, research partners and subscribers.

FEWER reports will focus on country and region-wide issues and ensure that such reporting reflects the interests and concerns of practitioners, researchers and policy makers.

FEWER will develop an internal assessment capacity in order toevaluate its performance and products for all members and stakeholders including funders.

\section{Membership}

- Membership is open to all producers and users of early warning information. There are two types of membership:

Consortium members that contribute to the provision of early warning information, analysis and strategy development.

Supporters of the Consortium that are interested in receiving the products of such analysis and will contribute financially to the Consortium in direct proportion to their capacity.

- The Consortium is the basis of a networkbetween member agencies and, as such, is essential for longterm sustainability.

- Members can participate/work in one or several activities according to their capacity, interests and mandates.

- Participation, effective consultation and dialogue, transparent and effective decision-making proc- esses are central to the success of the network.

\section{Activities}

The Consortium activities could be grouped under the following areas:

- developing a standard format for reporting and assessing risk;

- promoting and monitoring results of research and analysis;

- developing quality standards for the reliability of information and analysis;

- dissemination of analysis;

- evaluating tools and methodologies to support actors; and

- publishing relevant reports, tools, analysis for policy and learning purposes.

\section{Structure}

FEWER is a forum for persons interested in various aspects of early warning and early responses. The prevailing view is that its structure should permit wide and diverse membership from different stake holders including UN, IGOs, NGOs, research institutions, governments and others. The members will form a Consortium of interests in support of the advancement of policy, practise, action and education on issues of early warning, prevention and responses. Broadly speaking, this Consortium will support efforts to facilitate early warning research and analysis, inter-institutional learning and action as well as the development of tools to undertake such activities (such as indicators and other assessment capacities). The initiatives for the exchange of information and analyses led by a member or members of the Council of FEWER are described hereafter.

FEWER will be comprised of a Consortium of members, the purpose of whose activities will support the formation of a global network of information exchange, partnership for the promotion of research, analysis and capacity building in the areas of early warning, conflict prevention and early action. 
Roles and Responsibilities

\section{FEWER Consortium}

Open to UN, IGOs, NGOs, academic research units and all others including regional IGOs such as the OAU. Others who may wish to join can be accorded membership by the FEWER Council.

\section{FEWER Council}

The Council will comprise up to 25 members representing constituencies and institutions in areas of concern whether on early warning, prevention or conflict resolution. The FEWER Council represents linkages (hereafter known as working groups) within these institutions or initiatives which, in turn, will form the basis for a network of research nodes. Information and analysis deriving from these nodes may serve as the basis for FEWER reports.

The Council will take on responsibilities for broad policy making, including planning, membership, budgets, fundraising and annual reports. The Council will be headed by a Chairperson who will be assisted by a Deputy and representative from each of the major research projects supervised by various research institutions. Council appointments are for 3 years with options for an additional 2 years.

\section{FEWER Steering Committee}

TheSteering Committee will comprise 5 members including the Chair of the Council and Executive Director of the FEWER Secretariat (described hereafter) who will be a non-voting member. The responsibilities of the Steering Committee are: overall direct management of FEWER including the recruitment and hiring of personnel, financial management, approval of the research work plan (wherein priorities and themes are outlined) and approval of regional network research partnerships. Membership in the Steering Committee (apart from the Executive Director) is normally for 3 years, which may be varied with the approval of the Council.

\section{FEWER Secretariat}

The Secretariat will be headed by an Executive Director who will control and direct the development and implementation of policies and research planning, personnel, budgetary controls and reporting on expenditures to donors through the Steering Committee.

\section{FEWER Network of Working Groups}

Working groups will be organised around priorities and themes identified by the FEWER Secretariat in consultation with the working groups. The working groups may meet directly or electronically. The Director of Research of the FEWER Secretariat will liaise with a lead agency (nominated from the FEWER Council) and together they will coordinate the activities of the working groups as they support the research products of FEWER. As described in the functions of the FEWER Council above, the working groups will comprise a research network to supply first-hand reports and analysis as well as to advise FEWER on changes, directions and relevant issues for follow-up and referral in support of FEWER's research program and alert reports.

\section{FEWER Contact Group of Representatives of \\ Governments}

Government membership will comprise those representatives of governments interested in the work of FEWER and supportive of its network and products. Government representatives will have observer status in FEWER.

\section{Research Projects}

The current and future work of FEWER includes the establishment of: - standard formats for reporting conflict situations. These will ensure a basis for clarity and consistency in reports from different sources. Standard formats will also ensure the use of a common terminology which will help to avoid miscom- munication and support efforts in cross-conflict comparative analyses. The indicators used and field tested in the pilot projects will be evaluated after Phase I;

- a network that systematically identifies key actors in potential conflicts;

- effective ways to communicate between actors (producers and users);

- a Directory of Tools for Conflict Prevention. This directory, to be used by monitors, data gatherers and analysts in the field, will list and describe examples of the options available to UN agencies, IGOs, governments and NGOs to help prevent the escalation of violent conflict. It will be a tool to broaden the understanding of conflict prevention and to guide analysts in conflict areas by providing a wide variety of response options. The emphasis here is on a multi-tool approach with long- and shortterm recommendations for action; and

- research on the success or failure of policy prescriptions used by key actors in order to draw the main lessons learned from the application in different contexts and develop recommendations as to how to these tools are best used to prevent conflict.

\section{Current Field Research Initiatives}

FEWER currently has analytical capabilities in three pilot regions (former Soviet Union, West Africa and the Great Lakes region). One of the strengths of FEWER is to build on existing initiatives in order to avoid duplication, support on-going programs, utilize expertise in the field, and ensure cross-regional comparison and learning. For these reasons, the pilot projects are at different stages of implementation. Once incorporated into the FEWER framework, the pilot projects will provide regular conflict updates on each region in a standard format that will be widely disseminated. The projects will also provide short, focused and corroborated analyses on conflict situations. These reports 
will-identify inter alia populations at risk, local leaders, opportunities for conflict prevention and recommend options.

Phase I for the pilot projects is April 1997 to March 1998. The dates for dissemination of conflict assessments are July 1997, October 1997 with an evaluation in late January 1998. In Phase II, April 1998-December 1999, short reports are planned on a bi-monthly basis and with greater frequency during emergencies. FEWER also plans a series of occasional working papers on emerging issues and debates. In the future, an on-line journal as well as an early warning forum to encourage wide participation are envisioned. The current pilot projects are located in the following regions:

\section{Early Waming Network in the Former Soviet Union (EAWARN)}

The lead agency for EAWARN is the Center for the Study and Prevention of Conflict of the Russian Academy of Sciences. EAWARN was established in 1993 as a part of an international project on ethnic conflict management in the former Soviet Union. Its efforts have resulted in the development of a network of leading academic experts and policymakers from NGOs and government on ethnic issues and conflict management. The networkis comprised of thirty four country or regional groups that cover ten successor states from the former Soviet Union: Armenia, Azerbaijan, Georgia, Moldova, Latvia, Kazakhstan, Kirgizia, Tadjikistan, Russian and the Ukraine). The main mode of communication and dissemination of information is electronic mail.

EAWARN produces regular reports from its regional partners and bimonthly bulletins on important topics. The network convenes annual seminars for the purpose of interacting with other networks and strengthening its internal capacity.

EAWARN has developed a databank on ethnicity and conflict which includes demographic and sociocultural profiles of ethric groups and mi- norities, frequent updates on ethnic groupings in the various states and regions, survey reports, official documents (e.g., legislation). This data is available through the INTERNET. The dissemination of this information in English is limited due to lack of current funding.

\section{West African Research Network (WARN)}

The lead agency for WARN is the Prevention/Early Warning Unit, York University. The current focus of this project is Nigeria. WARN has issued a report on existing information (both in print and on the World Wide Web) on the situation in Nigeria. It has prepared a first draft report providing insights on the background and current issues in Nigeria.

WARN has begun to establish a network of academic institutions and NGOs in Nigeria, comprised of seventeen field officers, six regional coordinators, and one central coordinator. Communication and dissemination of information is managed via telephone, fax and email. The coordinators ensure the collection of country of origin information and analysis. This regional information and analysis is then passed on to the lead agency for a comparative assessment, analysis, report writing and dissemination.

\section{The Great Lakes Programme}

The lead agency for the Great Lakes Programme is International Alert. While International Alert has worked extensively in this region, it has decided to refrain from directly implementing the project. The decision is based on the fact that International Alert would like to ensure that any reports are independent from its advocacy objectives. In addition, International Alert would like to maintain the integrity and viability of its program on the ground as well as protect; as much as possible, the security of staff and partners.

International Alert will play a key role in identifying a partner agency in the region who will be responsible for designing, implementing and moni- toring the program. As part of this, a partnership between a local institution and an international one (based in the EU) will be built in order to ensure that the links between strategic options and analysis are geared to ongoing policy discussions and processes in the EU. During March and April, IA will finalize the criteria for the selection of partners and develop the Terms of Reference for their work. Resources for this project will go directly to the implementing institutions.

The project aims at creating an ongoing, reliable and credible assessment of the conflict situation in the Great Lakes region in order to collect information in a coherent manner from both primary and secondary sources. Information will be collected through a network of monitors and data gatherers in the field who will use a standard format. For the purpose of project facilitation there will be two to three annual seminars for monitors, analysts and the network of monitors on conflict analysis related issues and assessment/evaluation of work in progress. The first seminar in the region with monitors is likely to take place in August/September 1997. A concern will be to ensure that we are able to learn from existing activities in the field and other pilot projects.

\section{Evaluation of Pilot Projects}

The lead agency for this project is the Center for Preventive Action at the Council on Foreign Relations, New York. The Center for Preventive Action has projects in all three pilot node areas. This provides an excellent opportunity to develop evaluation mechanisms for the research provided by the nodes. By independently producing reports in all three regions, it is possible to compare the outcomes and contrast the findings with a view to refining and improving methodologies, approaches and linkages. Furthermore, as a party not itself involved in the research nodes, the Center for Preventive Action can assess the effectiveness of each pilot node, the methods used, and the final product in 
terms of utility for policy recommendations. Risks and Constraints of
Personnel in the Pilot Regions
Monitors and coordinators in the pilot
regions may be subject to some risk in
collecting information and undertaking
analyses. A protocol is under development
to both minimize those risks and provide
criteria for maximizing the safety of in-
country personnel. ID

\section{Contact Information for Member} Organizations

Kumar Rupesinghe International Alert

1 Glyn Street

London SEll 5HT

United Kingdom

Email: krupesinghe@international-

alert.org

Sharon Rusu

UN DHA, Palais des Nations CH-1211

Geneva 10

Switzerland

Email: sharon.rusu@dha.unicc.org

Gunther Bachler

Andreas Kohlschutter

Swiss Peace Foundation

Wasserwerkgasse 7

CH-3011 Bern

Switzerland

Email: spfbaechler@dial.eunet.ch

Barnett Rubin

Centre for Preventive Action

Council on Foreign Relations 58

East 68th Street

New York, NY 10021

Email: brubin@email.cfr.org

Alex Schmid

PIOOM Foundation

c/o LISWO, University of Leiden

Wassenaarseweg 52

2333 AK Leiden

The Netherlands

Emai1: schmid@rulfsw.leidenuniv.nl
Udo Janz

Andrei Dmitrichev

UNHCR, Centre for Documentation and

Research

Case Postale 2500

CH-1211 Geneva Z Depot Switzerland

Email: janz@unhcr.ch dmitrich@unhcr.ch

Valery Tishkov

Institute of Ethnology and

Anthropology

Russian Academy of Science

Leninskii Prospect 32a 117334

Moscow

Russia

Email: tishkov@ethno.msk.su

Alessandro Silj CSS-

Ethnobarometer Project Corso

Trieste, 62

00198 Rome

Italy

Email: cssroma@mbox.vol.it

Peter Ludlow

Frank Vereecken

Centre for European Policy Studies (CEPS)

Place du Congres 1

Brussels

Belgium

Emai1: 101721.1314OCompuServe.com

Howard Adelman

York Centre for International and

Security Studies

York University

York Lanes, 3rd Floor, 4700 Keele St.

North York, ON, M3J 1P3

Canada

Email: hadelman@yorku.ca CI

\section{Refuge}

Canada's Periodical on Refugees

is published six times a year by the Centre for Refugee Studies,

York University, Toronto.

Email: refuge@yorku.ca http://www.yorku.ca/research/crs

\section{Asylum: \\ A Moral Dilemma}

By W. Gunther Plaut

Toronto: York Lanes Press

ISBN 1-55014-239-9

192 pages, indexed; $\$ 19.90$.

Every year the refugee landscape changes, but only in that more problems are added, fewer are solved, and all become constantly more urgent. Fuelled by the explosion of the world's population, the quest for asylum is one of the most pressing problems of our age. Refugee-receiving nations-located frequently, but by no means exclusively, in the Western worldhave to respond to masses of humanity searching for new livable homes. Human compassion for these refugees can be found everywhere, but so can xenophobia and the desire to preserve one's nation, economic well being, and cultural integrity. The clash between these impulses represents one of the great dilemmas of our time and is the subject of Plaut's study. In exploring it, he provides a farranging inquiry into the human condition.

Thebook presents political, ethnic, philosophical, religious, and sociological arguments, and deals with some of the most troublesome and heartbreaking conflicts in the news.

Contents: The Issues; Questions Without Answers; Definitions; Religion, Natural Law, and Hospitality; A Look at History; Some Ethical Questions; Through the Lens of Sociobiology; Community and Individual; Contended Rights: To Leave, Return, Remain; The Practice; Refugees in Africa; Four Asian Lands; Glimpses of Europe and Central America; The North American Experience; The Sanctuary Movement;

A Final Look; Bibliography; Index. Asylum-A Moral Dilemma is simultaneously published in the United States by Praeger Publishers, and in Canada by York Lanes Press.

Refuge, Vol. 16, No.1 (May 1997) 